Journal of Patient-Centered

\title{
Pulmonary Blastomycosis in Vilas County, Wisconsin: Weather, Exposures and Symptoms
}

Dennis J. Baumgardner

Kiley A. Bernhard

Gina Egan

Follow this and additional works at: https://aah.org/jpcrr

Part of the Fungi Commons, and the Infectious Disease Commons

\section{Recommended Citation}

Baumgardner DJ, Bernhard KA, Egan G. Pulmonary blastomycosis in Vilas County, Wisconsin: weather, exposures and symptoms. J Patient Cent Res Rev. 2015;2:25-33. doi: 10.17294/2330-0698.1050

Published quarterly by Midwest-based health system Advocate Aurora Health and indexed in PubMed Central, the Journal of Patient-Centered Research and Reviews (JPCRR) is an open access, peer-reviewed medical journal focused on disseminating scholarly works devoted to improving patient-centered care practices, health outcomes, and the patient experience. 


\title{
Pulmonary Blastomycosis in Vilas County, Wisconsin: Weather, Exposures and Symptoms
}

\author{
Dennis J. Baumgardner, MD, ${ }^{1,2}$ Kiley A. Bernhard, MPH, ${ }^{2}$ Gina Egan, RN, BSN ${ }^{3}$ \\ ${ }^{1}$ Department of Family Medicine, Aurora University of Wisconsin Medical Group, Aurora Health Care, Milwaukee, WI \\ ${ }^{2}$ Center for Urban Population Health, Aurora Health Care, Milwaukee, WI \\ ${ }^{3}$ Vilas County Health Department, Eagle River, WI
}

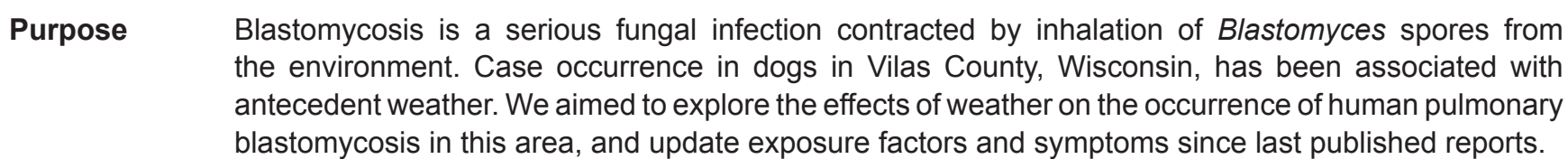

Methods Mandatory case reports were reviewed. Chi-square test was used for categorical data of exposures, comparing 1979-1996 ( $n=101)$ versus 1997-June $2013(n=95)$. Linear regression was used to model local weather data (available 1990-2013; n=126); Southern Oscillation Index (SOI), North Atlantic Oscillation Index (NAOI), and Wisconsin River water discharge (WRD) from the adjacent county (all available for 1984-2013; n=174); and case counts of known onset by warm (April-September) and cold (OctoberMarch) 6-month periods.

Results Distribution of pulmonary blastomycosis cases did not vary by season. Environmental exposures for the 1997-June 2013 group (mean age 45, 59\% male) were: residence $<400 \mathrm{~m}$ from waterway (76\%), excavation (42\%) and gardening (31\%), all similar to the 1979-1996 group. Fishing (23\% vs. 37\%; $\mathrm{P}=0.09)$ and hunting (15\% vs. $26 \%$; $\mathrm{P}=0.13)$ exposures were less common in 1997-June 2013, but not significantly different. Overall, $69 \%$ of cases recalled some prior soil-disturbing activities. Considering the 6-month warm/cold periods, $19 \%$ of variation is explained by a direct relationship with total precipitation from two periods prior $(\mathrm{P}=0.005)$. There was no association of case occurrence with $\mathrm{SOI}$, NAOI or WRD. Estimated annual incidence of blastomycosis for 1997-June 2013 was 27/100,000 compared with 44/100,000 for 1984-1996. Several symptoms were significantly less frequent in 2002-June 2013 compared to earlier years.

Conclusions As with dogs, human pulmonary blastomycosis occurrence is partially determined by antecedent precipitation. It is unclear if recent lower incidence rates are due to less opportunity for exposure to weather, reduced fungal virulence or random variation. (J Patient-Centered Res Rev. 2015;2:25-33.)

Keywords

Blastomyces dermatitidis, fungal ecology, mycoses, weather

Blastomycosis is a potentially life-threatening systemic and cutaneous fungal infection that affects humans, dogs and other animals. ${ }^{1,2}$ The etiologic dimorphic fungus, Blastomyces dermatitidis (and related cryptic species), is endemic to eastern North America and parts of India and Africa. ${ }^{1,3}$ Pulmonary disease is the most common manifestation of $B$. dematitidis infection, which occurs through the inhalation of fungal conidia

Correspondence: Dennis J. Baumgardner, MD,

1020 N. 12th Street, Suite \#4180, Milwaukee, WI, 53233,

T: 414-219-5191, F: 414-219-3116,

Email: dennis.baumgardner@aurora.org from the environment. $B$. dermatiditis conidia are usually eliminated by alveolar macrophages. If they are not eliminated, they rapidly convert to the yeast form at body temperature. The larger yeast forms more easily evade the immune system, and symptomatic or asymptomatic pulmonary disease may result. The pneumonia may be chronic, subacute or sometimes rapidly progressive with adult respiratory distress syndrome and death. ${ }^{1}$

Dogs, cats and humans acquire the fungus from similar environmental sites. ${ }^{4-6}$ Thus far, no animal reservoir has been identified. ${ }^{7} B$. dermatitidis tolerates a wide range of temperatures and periods of relative 
drought. ${ }^{8,9}$ Soil-disturbing activities have been associated with case clusters. ${ }^{6,10-12}$ The fungus is poorly competitive in the environment; however, its ability to survive potentially harsh conditions and rapid environmental change may enable it to temporarily propagate and infect humans and other animals. The microecologic niche of this organism remains incompletely defined. ${ }^{8-9}$ The ability to tolerate high levels of ammonia may confer a selective advantage in some situations. ${ }^{13}$

The growth and dispersal of other systemic fungal pathogens have been associated with antecedent weather. Prior precipitation, followed by drought, then by wind or excavation dust dispersal, has led to Coccidioides infection (the "grow and blow" hypothesis). ${ }^{14}$ A recent study suggested soil water storage and El Niño activity three years prior to case incidence and absolute air humidity the year before case incidence explained $49 \%$ of the yearly variance of paracoccidioidomycosis in an area of Brazil. ${ }^{15}$

A recent comprehensive series over 18 years of 219 cases of blastomycosis in dogs from Vilas County, Wisconsin, revealed that when warm (AprilSeptember) versus cold (October-March) weather time periods (6-month blocks) were the unit of analysis, total precipitation two periods prior was the single variable most predictive of the resultant case numbers among several weather parameters studied. ${ }^{16}$ This direct relationship explained $29 \%$ of case occurrence variance. When multiple weather parameters were examined, $67 \%$ of variation was explained by total precipitation two periods prior, and lower average temperature but higher maximum temperature one period prior. As dogs are considered harbingers of human blastomycosis, ${ }^{5,6,17-22}$ one might expect similar relationships between weather parameters and human blastomycosis.

The purpose of this study was to investigate the effects of antecedent weather, including El Niño activity, on human blastomycosis case occurrence in highly endemic Vilas County, Wisconsin. In addition, we sought to determine if preceding environmental exposures and symptoms in patients with pulmonary blastomycosis had changed over the past $12-18$ years.

\section{METHODS \\ Setting}

A description of Vilas County, Wisconsin, has previously been reported. ${ }^{17}$ Briefly, it is located at latitude $46^{\circ}$ North and longitude $89-90^{\circ}$ West, is $2,246 \mathrm{~km}^{2}$ in area, and has a (2012) population of 21,238 persons. The average elevation is approximately $518 \mathrm{~m}$. In July, the average high temperature in Eagle River (the county seat) is $25.6^{\circ} \mathrm{C}$ and the average low is $12.8^{\circ} \mathrm{C}$. Average high and low temperatures for January are $-6.1^{\circ} \mathrm{C}$ and $-17.8^{\circ} \mathrm{C}$, respectively. The average annual precipitation is $75 \mathrm{~cm}$. Snow covers the ground approximately 120 days per year, typically melting in April or May. Approximately $80 \%$ of the county is forested - most commonly mature upland mixed forest (specifically, a mixture of broadleaf, especially Betula, Populus and Acar saccharum, and needleleaf, especially Pinus strobus, Pinus resinosa and Abies balsamea, trees generally taller than $9 \mathrm{~m}$ ) - with the balance composed largely of waterways, including approximately $3,710 \mathrm{~km}$ of combined lake, river and stream shorelines. (Blastomycosis cases from this area have been associated with close proximity to waterways, recent excavation or soil-disturbing activities, and sand soils. ${ }^{6,18,19}$ )

\section{Case Identification}

This study was exempted by the local institutional review board. Human blastomycosis cases were drawn from a comprehensive registry of Vilas County residents, 1979-June 2013. All cases were laboratory confirmed by culture, direct microscopy, or histologic or cytologic examination. These cases included statemandated Blastomyces disease reports to the Vilas County Health Department from the onset of mandatory reporting in 1984 to June 2013. For 1979-1991 cases, additional case finding occurred through the three Vilas County hospitals and patient interviews. ${ }^{17}$ As mandatory reports were found to capture $96 \%$ of county residents with blastomycosis during 1984-1991, these records were used as a sole source of patient identification and information for 1992-June 2013, including two interim reports..$^{20,21}$ The entire data set of 190 patients from 1979 to June 2013 was used for analysis of environmental exposures. The time period 1984-June 2013 was used for calculation of case incidence rates.

Because pulmonary disease is the initial manifestation of blastomycosis (except in very rare cases of inoculation skin disease), ${ }^{1}$ only cases that included 
pulmonary disease were used for analysis in the remainder of the study, which involved symptoms of pulmonary disease and associations of weather and water data with case occurrence. Pulmonary symptoms were analyzed using the entire data set, 1979-June 2013. Pulmonary symptoms of individuals for 1979-2001 have been previously reported. ${ }^{21}$ Our data set was felt to be comprehensive regarding pulmonary blastomycosis cases from 1984 to June 2013. Therefore, the period 1984-June 2013 $(n=163)$ was used for analysis of associations between environmental exposures, weather and water discharge data, and case onset, except where noted below. Date of onset of pulmonary symptoms, by month, was used for statistical comparisons.

The estimated annual incidence rates for all cases of blastomycosis were calculated using case totals and U.S. Census population estimates for Vilas County from year $1990(17,707)$ for the time period 19841996, and from year 2005 (21,232) for time period 1997-June 2013.

\section{Weather Data}

Monthly weather data (maximum and minimum temperature; mean maximum, minimum and average temperature; average dew point; total precipitation; average wind speed; and maximum wind gust) were obtained for 1989-June 2013 from a nearby local weather station (KEGV, Eagle River, WI). Missing data (41/222 recordings of monthly temperature and 81/222 wind data points, all prior to 2009) were calculated by obtaining the equivalent reading from another Vilas County weather station (KARV, Arbor Vitae, WI), located $27 \mathrm{~km}$ west, and adjusting the reading with the difference between such readings from the two stations during three mid-point years (1999-2001), as in our previous report. ${ }^{16}$ The availability of monthly weather data beginning in 1989 resulted in human pulmonary blastomycosis cases for the period 1990-June 2013 $(n=126)$ being used for analysis of the associations between weather and case onset.

Monthly mean North Atlantic Oscillation Index (NAOI) data from 1983 to June 2013 were obtained from the U.S. National Oceanic and Atmospheric Administration (www.cpc.ncep.noaa.gov). The NAOI is based on surface sea-level pressure differences between the subtropical high and the subpolar low. This index is associated with the intensity and location of the North Atlantic jet stream and storm track as well as other features that result in changes in temperature and precipitation patterns. Strong positive phases (values) of the NAOI tend to be associated with abovenormal temperatures in eastern United States. Opposite patterns are seen with strong negative values.

Similarly, data on the monthly Southern Oscillation Index (SOI) from 1983 to June 2013 were obtained from the Australian Government Bureau of Meteorology (www.bom.gov.au/climate/current/soihtm1.shtml). The SOI, which is calculated using the pressure differences between Darwin, Australia and Tahiti, is associated with the development and intensity of El Niño (sustained values below -8) or La Niña (sustained values above 8) events in the Pacific Ocean.

Six-month "warm" (April-September) and "cold" (October-March) periods were used as the unit of analysis for weather data as in the previous study of dogs in this area. ${ }^{16}$

\section{River Water Discharge Data}

Monthly average discharge data, in cubic feet per second, were obtained from the U.S. Geological Survey for the recording site (USGS 05391000) on the Wisconsin River nearest to Vilas County (http:// waterdata.usgs.gov/nwis/monthly). This site is on the Wisconsin River at Rainbow Lake, in the county just south of Vilas County. Discharge rates should reflect water volumes and levels upstream, including in Vilas County. The Wisconsin River and its tributaries and connected lakes have been associated with the majority of Vilas County blastomycosis cases. ${ }^{17-20}$ Total discharge was calculated for each 6-month warm and cold period.

\section{Statistical Analysis}

MINITAB statistical software (State College, PA) was used for data analysis. Categorical data were analyzed using chi-square test with Yates' correction for environmental exposures (defined as residence within 0.25 miles of a waterway; or exposure to fishing, hunting, gardening or excavation 6 months prior to symptom onset) and symptoms in those with pulmonary disease. 
Consecutive pulmonary blastomycosis cases by 6-month warm and cold periods were taken as outcome variables and subjected to regression analysis using weather and river discharge parameters lagged by one or two 6-month (warm/cold) periods as predictor variables. Multivariate regression models were then constructed using statistically significant $(\mathrm{P}<0.05)$ variables with adjusted $\mathrm{R}^{2}>5 \%$ on univariate regression analysis.

\section{RESULTS}

The estimated annual incidence of blastomycosis was 27/100,000 for 1997-June 2013 and 44/100,000 for
1984-1996. Table 1 lists environmental exposures in these Vilas County patients, 1979-June 2013. Comparison is made between the years 1997June 2013 and a combination of previously published reports, which cover the years $1979-1996 .{ }^{17,20}$ Fishing and hunting were more common in the 1979-1996 period, but not significantly different. Overall, 69\% of cases in 1997-June 2013 recalled some prior soildisturbing activities. Table 2 lists symptoms in Vilas County patients with pulmonary blastomycosis from 1979 to June 2013 (pulmonary cases represented 91\% of all blastomycosis cases in this data set). Comparison is made between the years 2002-June 2013 (90\% of

Table 1. Environmental exposures in patients with blastomycosis

\begin{tabular}{lccc}
\hline Feature & 1997-June 2013 & 1979-1996 & 1979-June 2013 \\
\hline$\leq 1 / 4-$ mile waterway & $56 / 74(76 \%)$ & $93 / 116(80 \%)$ & $149 / 190(78 \%)$ \\
Fishing & $17 / 73(23 \%)$ & $34 / 92(37 \%)$ & $51 / 165(31 \%)$ \\
Hunting & $11 / 75(15 \%)$ & $23 / 90(26 \%)$ & $34 / 165(21 \%)$ \\
Gardening & $23 / 75(31 \%)$ & $27 / 77(35 \%)$ & $50 / 152(33 \%)$ \\
Excavation & $31 / 73(42 \%)$ & $36 / 92(39 \%)$ & $67 / 165(41 \%)$ \\
\hline
\end{tabular}

Denominators based on number of interviewed patients with a response to that item.

Table 2. Symptoms in patients with pulmonary blastomycosis

\begin{tabular}{|c|c|c|c|}
\hline Feature & 2002-June 2013 & $1979-2001^{21}$ & 1979-June 2013 \\
\hline Mean age, years & 50 & 44 & 45 \\
\hline Male, n (\%) & $25 / 45(56 \%)$ & $66 / 118(56 \%)$ & $91 / 163(56 \%)$ \\
\hline Smoking, $\mathrm{n}(\%)$ & $8 / 39(21 \%)$ & $\mathrm{n} / \mathrm{a}$ & $29 / 126(23 \%)^{*}$ \\
\hline Cough, n (\%) & $34 / 40(85 \%)$ & $106 / 118(90 \%)$ & $140 / 158(89 \%)$ \\
\hline Fatigue, n (\%) & $25 / 37(68 \%)$ & $63 / 66(95 \%)^{\dagger}$ & $88 / 103(85 \%)$ \\
\hline Dyspnea, n (\%) & $11 / 34(32 \%)$ & $64 / 118(54 \%)^{\#}$ & $75 / 152(49 \%)$ \\
\hline Fever, n (\%) & $22 / 39(56 \%)$ & $89 / 118(75 \%)^{\#}$ & $111 / 157(71 \%)$ \\
\hline Weight loss, n (\%) & $16 / 37(43 \%)$ & $78 / 118(66 \%)^{\#}$ & $94 / 155(61 \%)$ \\
\hline Chest pain, $n(\%)$ & $14 / 37(38 \%)$ & $74 / 118(63 \%)^{\#}$ & $88 / 155(57 \%)$ \\
\hline Night sweats, n (\%) & $19 / 39(49 \%)$ & $80 / 118(68 \%)$ & $99 / 157(63 \%)$ \\
\hline Hemoptysis, n (\%) & $6 / 38(16 \%)$ & $21 / 118(18 \%)$ & $27 / 156(17 \%)$ \\
\hline Muscle/joint pain, n (\%) & $20 / 39(51 \%)$ & $58 / 116(50 \%)$ & $78 / 155(50 \%)$ \\
\hline
\end{tabular}

Denominators based on number of interviewed patients with a response to that item.

*Smoking data not available for 1991-1995.

${ }^{+} P<0.001$ for 2002-2013 vs. 1979-2001, chi-square test with Yates correction.

${ }^{\#} P<0.05$ for 2002-2013 vs. 1979-2001, chi-square test with Yates correction. 
cases were pulmonary), and the previous report, ${ }^{21}$ which covered 1979-2001 (91\% were pulmonary). A number of symptoms were significantly less frequent in the more recent data set.

The seasonal distribution of pulmonary blastomycosis cases for the complete meteorological data set, 1984-2012, was: winter (December-February, $\mathrm{n}=35$ [22\%]), spring (March-May, $n=40$ [25\%]), summer (June-August, $\mathrm{n}=45$ [28\%]) and fall (SeptemberNovember, $n=42$ [26\%]); $P=0.9$. Similar to our study of local dogs, ${ }^{16}$ a majority of our human cases occurred May-October (91 cases) compared with NovemberApril (69 cases), but this difference was not significant in the present study $(\mathrm{P}=0.26)$.

Weather parameters varied significantly in this locale during the study period. The maximum temperature was $37^{\circ} \mathrm{C}$, the minimum $-42^{\circ} \mathrm{C}$. Monthly total precipitation varied from zero to $31.6 \mathrm{~cm}$, and maximum wind gusts ranged from 37 to $129 \mathrm{~km} / \mathrm{hour}$. Using warm versus cold weather time periods (6-month blocks) as the unit of analysis for human pulmonary blastomycosis cases during 1990June $2013(\mathrm{n}=126)$, total precipitation two periods prior was the single variable most predictive of the resultant case numbers. This was a direct relationship $\left(\mathrm{P}=0.005, \mathrm{~T}=3.03\right.$, adjusted $\left.\mathrm{R}^{2}=19 \%\right)$. The absolute change in total precipitation from one 6-month block to the prior block was significant when lagged by one $\left(\mathrm{P}=0.03\right.$, adjusted $\left.\mathrm{R}^{2}=11 \%\right)$ or two periods $(\mathrm{P}=0.03$, adjusted $\mathrm{R}^{2}=12 \%$ ); however, neither was significant when combined with total precipitation two periods prior in a multivariate regression model. No other 6-month maximum, minimum or mean temperature, wind or dew point parameters were significantly associated with case occurrence.

Regarding NAOI, SOI and Wisconsin River water discharge data in the case time period 1984June $2013(\mathrm{n}=163)$, only the net 6-month NAOI one period prior $\left(\mathrm{P}=0.03\right.$, adjusted $\mathrm{R}^{2}=6 \%$ ) and the maximum monthly negative-phase NAOI one 6-month period prior $\left(\mathrm{P}=0.02\right.$, adjusted $\mathrm{R}^{2}=9 \%$ ) were associated with case occurrence in univariate analysis. When these two variables were subjected to stepwise regression with 6-month period case occurrence as the outcome variable, only maximum monthly negative-phase
NAOI one 6-month period prior remained significant $\left(\mathrm{P}=0.02\right.$; adjusted $\left.\mathrm{R}^{2}=8.5 \%\right)$. For the time period 1990 June 2013 ( $n=126)$, a regression model including total precipitation two 6-month periods prior and maximum monthly negative-phase NAOI one period prior was constructed. This model explained $22 \%$ of the variance in 6-month period case occurrence; however, only total precipitation two periods prior remained significant $(\mathrm{P}=0.013)$.

Hemoptysis is generally considered a sign of chronic, rather than acute, blastomycosis, ${ }^{1}$ although our study of pulmonary blastomycosis in this area failed to delineate acute and chronic disease. ${ }^{21}$ As one might suggest that environmental associations are more easily observed by omitting nonacute cases, we reanalyzed our data, omitting cases with hemoptysis for the involved time periods. This did not change our results except for somewhat lower adjusted $\mathrm{R}^{2}$ in many comparisons due to reduction of statistical power.

From 1996 to June 2013, 71 patients were queried regarding prior pet disease; $11 / 71$ (15\%) reported prior blastomycosis in an owned dog (no cat blastomycosis reported).

\section{DISCUSSION}

In this highly endemic Wisconsin county, diagnosed cases of laboratory-confirmed pulmonary blastomycosis appear to be occurring less frequently, and with generally fewer symptoms, in recent years (1997-June 2013). The lower proportions of several symptoms, particularly weight loss (presumably indicative of more profound or longer duration disease), suggests that, recently, diagnosis of blastomycosis may be occurring in milder cases of disease or earlier in the course. However, the rate of hemoptysis (also considered a sign of later-stage disease $^{1,22}$ ) has remained stable and low through the years. The recognition of less symptomatic cases of a disease would be expected to result in higher incidence rates than previously reported. Instead, this study documents lower recent blastomycosis incidence rates.

Given that blastomycosis is an environmentally acquired disease, lower incidence rates could reflect less opportunity for human exposure to the etiologic 
fungus. This could involve less engagement by humans in activities that result in contact with B. dermatitidis, an overall decrease in the proportion of the local environment inhabited by the organism or a decrease in fungal density specifically in those parcels frequented or disturbed by humans. Alternatively, the current predominant fungal strains in the local environment could have reduced pathogenicity compared to years past.

The data from the present study suggests that subjects with blastomycosis in this area recall engagement in fewer specific outdoor activities (e.g. hunting, fishing, gardening) in more recent, compared to earlier, time periods. These differences are not significant. In addition, we have no data on the intensity or duration of these activities, or comparison with a control group of subjects without history of blastomycosis. The relative densities of various microbial species may be highly dynamic in soil and related environments. ${ }^{23}$ It is known, or hypothesized, that a number of other soil microorganisms are inhibitors of $B$. dermatitidis, ${ }^{8}$ and that the ability to grow or tolerate a number of environmental substances may afford this fungus, known to be relatively slow-growing compared to many potential competitors, a relative survival advantage in the environment, even if transient. ${ }^{13,24}$

The present study suggests that, like the previous study of dogs in this area, ${ }^{16}$ antecedent precipitation may partially determine subsequent cases of human blastomycosis in this region. Dogs have long been considered harbingers of human blastomycosis, ${ }^{25}$ and in this area there have been a mixed human and dog outbreak, ${ }^{6}$ same-household cases over time, ${ }^{26}$ and similar geographic distributions of human and dog cases. ${ }^{17-19}$ In highly endemic Vilas County and vicinity, dog cases of blastomycosis per capita occur at a rate 14-fold higher than that of humans. ${ }^{18}$ This is the likely reason why our prior study of dogs revealed a more robust statistical association of cases with antecedent precipitation and other weather parameters. ${ }^{16}$ Nonetheless, it is reassuring that the present study of human blastomycosis cases revealed a similar association with antecedent precipitation as the previous study of dogs.
As discussed previously, ${ }^{16}$ the association of blastomycosis cases with prior precipitation may be particularly important in light of an association of cases with sand soils and waterways in the same region. ${ }^{19,27}$ In brief, sand soils, compared to other soil types, are particularly prone to daily temperature extremes and wet-dry cycles, especially where the forest canopy is open along waterways. Periods of relative drought may provide a temporary selective advantage for $B$. dermatitidis due to its ability to tolerate reduced moisture ${ }^{8,9}$ and elevated level of ammonia (which generally increases in concentration as moisture decreases, particularly in sand soils with intermittent nitrogenous deposits such as animal droppings ${ }^{13,23}$ ). Periods of increased moisture also appear to be important for growth of $B$. dermatitidis, and for natural conidia dispersal. ${ }^{28}$ The proper timing and amounts of precipitation may be important regarding subsequent acquisition of the fungal spores from the environment.

The hypothesis that current predominant Blastomyces strains in the environment in this area could have relatively reduced pathogenicity, compared to strains in the past, is intriguing. Strains of lesser virulence likely exist in the environment. $B$. dermatitidis strains with reduced virulence have been known for some time, but may have resulted from serial passage on artificial media and storage in laboratories. ${ }^{29}$ One strain isolated in vitro from a woodpile in Vilas County $^{30}$ is nonpathogenic in murine models (Bruce Klein, personal communication, and a report from Broad Institute ${ }^{31}$ ). Whether this strain (ER-3/ATCC MYA 2586) is inherently nonpathogenic is not known. Genetic diversity has previously been demonstrated in Wisconsin's B. dermatitidis strains. ${ }^{32-34}$ Recently, genetic evidence has been provided for the existence of a cryptic (previously unrecognized) separate species within what has heretofore been considered $B$. dermatitidis, and the two species likely vary regarding virulence. ${ }^{35}$ For example, two of our Vilas County strains (ER-3 and ERC-2/ATCC MYA 2585) are actually split between the two proposed species, ${ }^{35}$ and they have previously been shown to exhibit different growth rates on various artificial media. ${ }^{24}$ Recent Wisconsin studies have demonstrated differing clinical features among different genetic groups of B. dermatitidis in humans ${ }^{34}$ and dogs, ${ }^{36}$ and perhaps 
among different human ethnic groups. ${ }^{37}$ In addition, a Canadian case series reported by Light et al. suggested the possibility of differing strain virulence (as determined by proportion of extrapumonary cases), perhaps influenced by seasonal environmental effects. ${ }^{38}$ Small numbers of extrapulmonary cases during 1979-June 2013 precluded similar analysis of our Vilas County data.

The uniform seasonal distribution of human cases in this area has been previously reported. ${ }^{39}$ Although not significant in this study, the May-October predominance seen in local dog cases ${ }^{16}$ also was seen in humans.

Thus, $B$. dermatitidis strains likely vary by virulence according to the specific environmental location and perhaps according to the particular season or time period. Whether or not preceding weather conditions specifically influence the relative predominance of lesser-virulent $B$. dermatitidis strains, or if lesservirulent strains are becoming more predominant in recent years, cannot be inferred from previous studies or the present investigation. It is intriguing to consider the recent lower incidence rates in Vilas County as being the result of a greater proportion of infections from less virulent strains (with resultant less diagnosis and reporting of asymptomatic and minimally symptomatic blastomycosis, despite overall improved diagnosis of milder cases) versus less opportunity for exposure due to recent changes in type of outdoor activities or their duration.

The proportion of pet owners in our study who had at least one prior dog with blastomycosis is not surprising. Cases of dog blastomycosis frequently precede, follow or occur simultaneously with human cases. ${ }^{5,6,25,26}$ The ratio of dog to human cases in Vilas County is approximately $14: 1 .^{17,18}$ In a mail survey study of a highly endemic area of Vilas County, 20\% of dogs over a 15-year period were reported to have had blastomycosis. ${ }^{40}$ Both that study, and the present one, could include some return/recall bias.

Clinically, as has been previously noted, ${ }^{21}$ cough is the predominant symptom in human pulmonary blastomycosis, with fever and fatigue occurring in a majority of cases. No one constellation of symptoms is pathognomonic for blastomycosis. The percentage of pulmonary symptoms present in our subjects from 1997 to June 2013 (Table 2) compares very favorably to that from patients diagnosed from 1999 to 2009 through Marshfield Clinic, Marshfield, WI. ${ }^{34}$ The differential diagnosis is broad, and pulmonary blastomycosis may be difficult to differentiate from a wide variety of respiratory tract illnesses. ${ }^{41}$

This study was subject to several limitations. It is a retrospective study from a single geographic location that may not be representative of other populations. Clinical data was limited to state-mandated reports; a detailed medical record review was not performed. Similarly, specific details regarding duration, intensity and explicit types of outdoor exposures were generally not available. We were limited to the local and global weather and water discharge data that was accessible. Despite the setting in an area very highly endemic for blastomycosis, the moderate sample size of this study likely precluded robust analysis of all the weather parameters.

\section{CONCLUSIONS}

This epidemiologic survey of patients with blastomycosis in Vilas County, Wisconsin, is potentially helpful to patients with this disease in several ways. Patients want to know how and why they contracted this potentially fatal fungal disease. While this report should not in any way suggest that one should explain pulmonary blastomycosis cases as a consequence of the weather, it nonetheless illustrates the complexities involved in acquisition of this disease, likely a combination of environmental and temporal factors, host susceptibility and opportunity for exposure to the ecological niche of the involved fungus. This list of pulmonary symptoms should again remind clinicians to include pulmonary blastomycosis in the differential diagnosis of a wide variety of respiratory illness presentations. Blastomyces dermatitidis is predicted to be present, ${ }^{42}$ and blastomycosis does occur, in our catchment area in eastern Wisconsin. ${ }^{43}$ In addition, blastomycosis is being recognized in traditionally low endemic areas of Wisconsin..$^{44} \mathrm{~A}$ high index of suspicion is warranted by all clinicians to avoid missing this potentially serious fungal infection. 


\section{Patient-Friendly Recap}

- Pulmonary blastomycosis is a serious fungal infection of the lungs.

- Increased rain and snow predicted an increase in the future occurrence of this disease in dogs in Vilas County in northern Wisconsin.

- The authors report that these weather conditions similarly affected the number of future blastomycosis cases in people residing in the same area.

- Other factors frequently associated with human blastomycosis continue to include living near a waterway, excavating and other soil-disturbing activities.

- Favorably, cases of blastomycosis have decreased in the last 15 years. There are several possible reasons for this.

\section{Acknowledgments}

This study was supported in part by Aurora Health Care Foundation Fund "505-3201 - Infectious Disease." The authors acknowledge the assistance of Laurel Dreger, Vilas County Health Department, Eagle River, WI.

\section{Conflicts of Interest}

None.

\section{REFERENCES}

1. Chapman SW, Sullivan DC. Blastomyces dermatitidis. In: Mandell GL, Bennett JE, Dolin R (eds). Principles and Practice of Infectious Diseases, Seventh Edition. Philadelphia, PA: Elsevier, 2010, pp. 3319-32.

2. Baumgardner DJ. Blastomycosis. In: Domino FJ, Baldor RA, Golding J, Grimes JA (eds). The 5-Minute Clinical Consult 2015, 23rd Edition. Philadelphia, PA: Wolters Kluwer Health, 2014.

3. Al-Doory Y, DiSalvo AF (eds). Blastomycosis. New York, NY: Plenum, 1992.

4. Furcolow ML, Busey JF, Menges RW, Chick EW. Prevalence and incidence studies of human and canine blastomycosis. II. Yearly incidence studies in three selected states, 1960-1967. Am J Epidemiol. 1970;92:121-31.

5. Armstrong CW, Jenkins SR, Kaufman L, Kerkering ${ }^{\mathrm{TM}}$, Rouse BS, Miller GB Jr. Common-source outbreak of blastomycosis in hunters and their dogs. J Infect Dis. 1987;155:568-70.

6. Baumgardner DJ, Burdick JS. An outbreak of human and canine blastomycosis. Rev Infect Dis. 1991;13:898-905.

7. Baumgardner DJ, Summerbell R, Krajden S, et al. Attempted isolation of Blastomyces dermatitidis from native shrews in northern Wisconsin, USA. Med Mycol. 2005;43:413-6.
8. DiSalvo AF. The ecology of Blastomyces dermatitidis. In: AlDoory Y, DiSalvo AF (eds). Blastomycosis. New York, NY: Plenum, 1992, pp. 43-73.

9. Restrepo A, Baumgardner DJ, Bagagli E, et al. Clues to the presence of pathogenic fungi in certain environments. Med Mycol. 2000;38 Suppl 1:67-77.

10. Kitchen MS, Reiber CD, Eastin GB. An urban epidemic of North American blastomycosis. Am Rev Respir Dis. 1977;115:1063-6.

11. Proctor ME, Klein BS, Jones JM, Davis JP. Cluster of pulmonary blastomycosis in a rural community: evidence for multiple high-risk environmental foci following a sustained period of diminished precipitation. Mycopathologia. 2002;153:113-20.

12. Blondin N, Baumgardner DJ, Moore GE, Glickman LT. Blastomycosis in indoor cats: suburban Chicago, Illinois, USA. Mycopathologia. 2007;163:59-66.

13. Baumgardner DJ. Microecology of Blastomyces dermatitidis: the ammonia hypothesis. Med Mycol. 2009;47:745-52.

14. Comrie AC, Glueck MF. Assessment of climatecoccidioidomycosis model: model sensitivity for assessing climatologic effects on the risk of acquiring coccidioidomycosis. Ann N Y Acad Sci. 2007;1111:83-95.

15. Barrozo LV, Mendes RP, Marques SA, Benard G, Silva ME, Bagagli E. Climate and acute/subacute paracoccidioidomycosis in a hyper-endemic area in Brazil. Int $J$ Epidemiol. 2009;38:1642-9.

16. Baumgardner DJ, Paretsky DP, Baeseman ZJ, Schreiber A. Effects of season and weather on blastomycosis in dogs: Northern Wisconsin, USA. Med Mycol. 2011;49:49-55.

17. Baumgardner DJ, Buggy BP, Mattson BJ, Burdick JS, Ludwig D. Epidemiology of blastomycosis in a region of high endemicity in north central Wisconsin. Clin Infect Dis. 1992;15:629-35.

18. Baumgardner DJ, Paretsky DP, Yopp AC. The epidemiology of blastomycosis in dogs: north central Wisconsin, USA. J Med Vet Mycol. 1995;33:171-6.

19. Baumgardner DJ, Steber D, Glazier R, et al. Geographic information system analysis of blastomycosis in northern Wisconsin, USA: waterways and soil. Med Mycol. 2005;43:117-25.

20. Baumgardner DJ, Brockman K. Epidemiology of human blastomycosis in Vilas County, Wisconsin. II: 1991-1996. WMJ. 1998;97:44-7.

21. Baumgardner DJ, Halsmer SE, Egan G. Symptoms of pulmonary blastomycosis: northern Wisconsin, United States. Wilderness Environ Med. 2004;15:250-6.

22. Varkey B. Blastomycosis in children. Semin Respir Infect. 1997; 12:235-42.

23. Morris SJ, Blackwood CB. The ecology of soil organisms. In: Paul EA (ed). Soil Microbiology, Ecology and Biochemistry, Third Edition. Burlington, MA: Academic Press, 2007, pp. 195-229.

24. Baumgardner DJ, Laundre B. Studies on the molecular ecology of Blastomyces dermatitidis. Mycopathologia. 2001;152: 51-8.

25. Sarosi GA, Eckman MR, Davies SF, Laskey WK. Canine blastomycosis as a harbinger of human disease. Ann Intern Med. 1979;91:733-5.

26. Baumgardner DJ, Paretsky DP. Blastomycosis: more evidence for exposure near one's domicile. WMJ. 2001;100:43-5. 
27. Archer JR, Trainer DO, Schell RF. Epidemiologic study of canine blastomycosis in Wisconsin. J Am Vet Med Assoc. 1987;190:1292-5.

28. McDonough ES, Wisniewski TR, Penn LA, Chan DM, McNamara WJ. Preliminary studies on conidial liberation of Blastomyces dermatitidis and Histoplasma capsulatum. Sabouraudia. 1976;14:199-204.

29. Stevens DA, Brummer E, DiSalvo AF, Ganer A. Virulent isolates and mutants of Blastomyces in mice: a legacy for studies of pathogenesis. Semin Respir Infect. 1997;12:189-95.

30. Baumgardner DJ, Paretsky DP. The in vitro isolation of Blastomyces dermatitidis from a woodpile in north central Wisconsin, USA. Med Mycol. 1999;37:163-8.

31. Broad Institute. Blastomyces dermatitidis ER-3. http://www. broadinstitute.org/annotation/genome/dimorphic_fungi/ GenomeDescriptions.html\#<i $>$ Blastomyces dermatitidis $</ \mathbf{i}>$ ER-3. Accessed April 4, 2014.

32. McCullough MJ, DiSalvo AF, Clemons KV, Park P, Stevens DA. Molecular epidemiology of Blastomyces dermatitidis. Clin Infect Dis. 2000;30:328-35.

33. Meece JK, Anderson JL, Klein BS, et al. Genetic diversity in Blastomyces dermatitidis: implications for PCR detection in clinical and environmental samples. Med Mycol. 2010;48: 285-90.

34. Meece JK, Anderson JL, Gruszka S, Sloss BL, Sullivan B, Reed KD. Variation in clinical phenotype of human infection among genetic groups of Blastomyces dermatitidis. J Infect Dis. 2013;207:814-22.

35. Brown EM, McTaggart LR, Zhang SX, Low DE, Stevens DA, Richardson SE. Phylogenetic analysis reveals a cryptic species Blastomyces gilchristii, sp. nov. within the human pathogenic fungus Blastomyces dermatitidis. PLoS One. 2013;8:e59237.
36. Anderson JL, Sloss BL, Meece JK. Clinical and molecular epidemiology of veterinary blastomycosis in Wisconsin. $B M C$ Vet Res. 2013;9:84.

37. Roy M, Benedict K, Deak E, et al. A large community outbreak of blastomycosis in Wisconsin with geographic and ethnic clustering. Clin Infect Dis. 2013;57:655-62.

38. Light RB, Kralt D, Embil JM, et al. Seasonal variations in the clinical presentation of pulmonary and extrapulmonary blastomycosis. Med Mycol. 2008;46:835-41.

39. Baumgardner DJ, Baeseman ZJ, Schreiber A. Geographic distribution of human blastomycosis by season in northern Wisconsin. (abstr.) WMJ. 2008;107:339-340.

40. Baumgardner DJ, Turkal NW, Paretsky DP. Blastomycosis in dogs: a fifteen-year survey in a very highly endemic area near Eagle River, Wisconsin, USA. Wild Environ Med. 1996;7:1-8.

41. Baumgardner DJ, Temte JL, Gutowski E, et al. The differential diagnosis of pulmonary blastomycosis using case vignettes: a Wisconsin Network for Health Research (WiNHR) study. WMJ. 2011;110:68-73.

42. Reed KD, Meece JK, Archer JR, Peterson AT. Ecologic niche modeling of Blastomyces dermatitidis in Wisconsin. PLoS One. 2008;3:e2034.

43. Johnson KT, Bernhard KA, Baumgardner DJ. Demographic features of Aurora blastomycosis cases, 2007-2013. (abstr.) J Patient-Centered Res Rev. 2014;1:151-52.

44. Pfaff BL, Agger WA, Volk TJ. Blastomycosis diagnosed in a nonhyperendemic area. WMJ. 2014;113:11-8.

(C) 2015 Aurora Health Care, Inc. 